\title{
Tobacco use and other aspects related to smoking among school-going adolescents aged 13-15 years in Malaysia: Analysis of three cross-sectional nationally representative surveys in 2003, 2009 and 2016
}

\author{
Kuang H. Lim', Sumarni M. Ghazali', Hui L. Lim², Chee C. Kee ${ }^{1,3}$, Yong K. Cheah', Balvinder S. G. Pradhaman Singh', Pei \\ P. Heng', Chien H. Teh', Yoon L. Cheong ${ }^{1}$, Jia H. Lim ${ }^{5}$
}

\begin{abstract}
INTRODUCTION Periodic surveys on tobacco use patterns and other aspects of tobacco use among school-going adolescents in Malaysia provide information on the effectiveness of anti-smoking measures implemented. However, such information is limited in Malaysia. We investigated the prevalence of smoking and other related aspects among middle-secondary school students in Malaysia from the years 20032016 to fill this gap.

METHods We analyzed data from the Global Youth Tobacco Survey (GYTS) 2003, GYTS 2009, and the Tobacco and Electronic Cigarette Survey among Malaysia Adolescents (TECMA) 2016. The surveys employed multistage sampling to select representative samples of adolescents attending secondary school in Malaysia. Data were collected using a pre-validated self-administered anonymous questionnaire adopted from the GYTS.

RESULTS Between 2003 and 2016, major changes occurred in which there were reductions in the prevalence of ever smoking, current smoking, and susceptibility to smoking. Reductions were also observed in exposure to SHS in public places and in the home. The proportion of school-going adolescents who support a ban on smoking in public places increased between 2013 to 2016, and there was a significant reduction in the proportion of respondents that were offered 'free' cigarettes by tobacco company representatives. However, there was no difference in the proportion of adolescents who initiated smoking before the age of 10 years and current smokers seeking advice to quit smoking across the time period.

CONCLUSIONS Our study indicates that the smoking policies and measures have been effective in reducing smoking prevalence, secondhand smoke exposure, and access to cigarettes, among school-going adolescents in Malaysia. However, measures to reduce smoking initiation and increase smoking cessation need to be strengthened to reduce the burden of smoking-related diseases in Malaysia in the long-term.
\end{abstract}

\author{
AFFILIATION \\ 1 Special Research Centre, \\ Institute for Medical Research, \\ Kuala Lumpur, Malaysia \\ 2 Department of Oncology, \\ Hospital Sulltan Ismail, Johor \\ Bahru, Malaysia \\ 3 Sector for Biostatistics and \\ Data Repository, National \\ Institute of Health, Shah \\ Alam, Malaysia \\ 4 School of Economics, \\ Finance and Banking, \\ Universiti Utara Malaysia, \\ Sintok, Malaysia \\ 5 School of Pharmacy, \\ Monash University Malaysia, \\ Subang Jaya, Malaysia
}

CORRESPONDENCE TO Kuang H. Lim. Special Research Centre, Institute for Medical Research, Jalan Pahang, 50588 Kuala Lumpur, Malaysia. E-mail: keelimkota@yahoo.com

\section{KEYWORDS}

tobacco use, school-going adolescents, global youth tobacco survey, secondhand smoke

Received: 6 May 2020 Revised: 12 August 2020

Accepted: 3 September 2020

\section{INTRODUCTION}

Tobacco use is one of the most important preventable causes of premature death, disease and disability around the world ${ }^{1}$. Smoking is also a significant cause of health problems in Malaysia ${ }^{2}$, smoking-related disease having been a major contributor to mortality since $1980^{3}$, with a third of diseases due to smoking ${ }^{4}$. Several nationwide studies have reported that more than $70 \%$ of smokers started to smoke before the age of 18 years; this is in line with other studies conducted 
both locally and in other countries ${ }^{2,4,5}$, which revealed that smoking is a learned behavior and usually begins during adolescence. The earlier individuals start smoking, the higher their risk to develop diseases related to smoking ${ }^{6}$ and the less likelihood to cease smoking during their adulthood ${ }^{7,8}$. Therefore, action to prevent non-smoking youth from smoking is among the initiatives included in the policy of the Ministry of Health, so that the problem of smoking-related illness in Malaysia can be addressed ${ }^{3}$.

The Malaysian government, through several ministries, has introduced policies and measures to reduce the incidence of smoking among Malaysian adolescents. These initiatives include health promotion activities such as 'Young Doctor Programmes' to teach youth about the health risks of smoking ${ }^{9}$, introduction of the Control of Tobacco Regulation 2004, which includes the prohibition of access to tobacco for people aged $<18$ years, a ban on the sale of cigarettes in a 'kiddy-pack', and the expansion of smoke-free public areas ${ }^{10}$. All policies that were introduced were in-line with the Framework Convention of Tobacco Control ${ }^{11}$, which was ratified by the Malaysian Government in 2005. In addition, the Malaysian government (i.e. Ministry of Finance) has also changed the taxation structure of smoking from the weight to stick of cigarettes, thus increasing the price of cigarettes as a monetary measure to reduce the demand for cigarette products ${ }^{3}$.

The Framework Convention of Tobacco Control (FCTC) suggested the following six MPOWER measures to reduce the demand for tobacco and to monitor the progress of anti-smoking in member countries $^{11}$ : Monitor tobacco use and prevention policies; Protect people from tobacco smoke; Offer help to quit tobacco use; Warn about the danger of tobacco; Enforce bans on tobacco advertising, promotion and sponsorship; and Raise taxes for tobacco. However, no due attention was given to the monitoring of smoking among middle-school students aged 13-15 years in Malaysia. Although studies among young people smoking in Malaysia have increased since 2006, most of the studies have concentrated on smoking prevalence and other factors associated with smoking among youth ${ }^{12,13}$. Therefore, we examined the following four MPOWER measures: prevalence of cigarette smoking, secondhand smoke exposure, smoking cessation, access to tobacco and sponsorship, as well as susceptibility to smoking, using data from three national smoking surveys to obtain a clearer picture of the status of tobacco use and control among middle-school adolescents in Malaysia.

\section{METHODS}

\section{Source of data}

Data were analyzed from three national smoking surveys: The Global Youth Tobacco Survey (GYTS) 2003, GYTS 2009, and the Tobacco and Electronic Cigarette Survey among Malaysia Adolescents (TECMA) 2016. The surveys GYTS 2003 and GYTS 2009 used a two-stage cluster sampling design to select a representative sample of lower secondary students aged 13-15 years enrolled in public schools under the Ministry of Education, Malaysia. In the first stage, secondary schools were sampled based on probability of selection equal to school enrolment size; in the second stage, classes within the chosen schools were sampled using systematic equal-probability sampling with random start. All students in the selected classes were invited to participate in the survey. A total of 50 secondary schools were selected for the study. Ethical approval was obtained from the Medical Research Ethical Committee, Ministry of Health Malaysia, and Ethical Committee, Ministry of Education, prior to the study. Written consent was obtained from both the parents/guardians of all selected participants and the participants themselves, prior to the interview session. The Director-General of Health, Malaysia, gave permission for publication of the study. The authors may be contacted for data requests.

In the TECMA survey, cross-sectional and multistage cluster sampling was employed to select a representative sample of school-going adolescents aged 10-19 years. However, for the purpose of this study, only data from respondents aged 13-15 years were selected for analysis. In the TECMA sampling design, the primary strata consisted of states in Malaysia, and the secondary strata were urban and rural areas within the states. The primary sampling units were primary and secondary schools in each state while the secondary sampling units were classes in the selected schools. All students in the selected classes were eligible to participate in the study. In total, 138 schools were selected ( 82 urban and 56 rural). A full description of the study methodology 
is available elsewhere ${ }^{14}$. All three surveys utilized the latest sampling frame provided by Ministry of Education, Malaysia.

The questionnaire for GYTS 2003 was adopted from the GYTS Core Questionnaire with Optional Questions ${ }^{15}$. A panel of experts selected the countryspecific optional items to be included in the final questionnaire. The final country questionnaire was translated into the local language and back-translated to check for accuracy. GYTS country research coordinators conducted focus groups of students aged 13-15 years to further test the accuracy of the translation and student understanding of the questions. Face validity was established through a pretest among 30 secondary school students aged 13-15 years. The same questionnaire was used in the GTYS 2009 and TECMA 2016 surveys. The questionnaire assessed smoking prevalence, perceptions and attitudes about tobacco, access to and availability of tobacco products, susceptibility to initiate smoking, exposure to secondhand smoke, school curriculum, media and advertising, and smoking cessation.

\section{Definition of smokers}

Ever smoker ${ }^{16}$ : Respondents who reported to have smoked at least once in their lifetime.

Current smoker ${ }^{17}$ : Those who smoked cigarettes on 1 or more days in the past 30 days.

Never smoker ${ }^{17}$ : A person who had never tried or experimented with cigarette smoking, even one or two puffs.

\section{Statistical analyses}

All statistical analyses were performed using SPSS version 22. A weighting factor was applied to each subject to adjust for non-response (by school, class, and student) and variation in the probability of selection at the school, class, and student levels (for GYTS 2003 and GYTS 2009), whilst for TECMA, the sample was weighted based on the variation in the probability of selection at the state, urban/rural, school, class, and student levels. This was followed by a final adjustment summing up the weights by grade and gender to the population of schoolchildren in the selected grades in each sample site. Differences were considered statistically significant if confidence intervals did not overlap. All analyses were performed at the 95\% confidence level using the complex sample analysis.

\section{RESULTS}

\section{Sociodemographic characteristics}

The number of participants in each study were: 3437 for GYTS 2003; 3185 for GYTS 2009; and 5087 for the TECMA 2016. The gender ratio was similar in all three surveys and one-third of the respondents studied in Form 1 (age 12-13 years). There was no significant difference in the distribution of subjects by gender and Form (school grade) between the surveys (Table 1).

\section{Prevalence of smoking}

Almost one in three school-going adolescents (27.3\%) had ever smoked in 2016 (Table 2) and approximately 1 in 5 ever smokers of both genders had initiated smoking before the age of 10 years. More than 1 in 10 students were current cigarette smokers $(14.8 \%)$ and almost $10 \%$ of never smokers reported likely to initiate smoking in the next year. There was a significant reduction in the proportion of ever smokers, current smokers, and susceptible to smoking, from 2003 to 2009 across gender. The

\section{Table 1. Characteristics of respondents of surveys GYTS 2003, GYTS 2009 and TECMA 2016}

\begin{tabular}{|c|c|c|c|c|c|c|c|c|c|}
\hline \multirow[t]{2}{*}{ Variable } & \multicolumn{3}{|c|}{ GYTS 2003} & \multicolumn{3}{|c|}{ GYTS 2009} & \multicolumn{3}{|c|}{ TECMA 2016} \\
\hline & $N *$ & $n * *$ & $\%(95 \% \mathrm{CI})$ & $N *$ & $n * *$ & $\%(95 \%$ CI $)$ & $\mathbf{N} *$ & $n * *$ & $\%(95 \%$ CI $)$ \\
\hline \multicolumn{10}{|l|}{ Gender } \\
\hline Male & 592135 & 1736 & $50.6(47.6-53.6)$ & 656798 & 1640 & $50.7(49.0-52.5)$ & 761489 & 2713 & $52.7(50.1-55.3)$ \\
\hline Female & 578121 & 1701 & $49.4(46.4-52.4)$ & 638140 & 1582 & $49.3(47.0-51.0)$ & 682650 & 2374 & $47.3(44.7-49.9)$ \\
\hline \multicolumn{10}{|l|}{ Education level } \\
\hline Form 1 (age 12-13) & 406861 & 1267 & $34.9(29.3-41.4)$ & 438271 & 1035 & $33.9(32.3-35.6)$ & 478238 & 1636 & $33.1(21.9-46.6)$ \\
\hline Form 2 (age 13-14) & 402542 & 1236 & $327(28.0-37.7)$ & 426930 & 974 & $33.1(31.4-34.8)$ & 407473 & 1838 & $28.2(20.8-37.1)$ \\
\hline Form 3 (age 14-15) & 377499 & 921 & $32.4(26.8-38.5)$ & 426072 & 1205 & $33.0(31.4-34.6)$ & 558428 & 1813 & $38 . .7(27.4-51.3)$ \\
\hline
\end{tabular}

${ }^{*} \mathrm{~N}$ : estimated population. ${ }^{* *} \mathrm{n}$ : sample population. 
study also found that the proportion of ever, current, and susceptible to smoking, was significantly higher among males compared to females, across the surveys.

\section{Secondhand smoke exposure}

More than half of the respondents reported exposure to secondhand smoke (SHS) in public areas (other than the home) (53.8\% in 2016 and $63.5 \%$ in 2009). Two out of five respondents reported exposure to SHS at home in the past week. The majority (almost $90 \%$ ) of TECMA 2016 respondents were in favor of a ban on smoking in public places. The prevalence of SHS exposure was significantly lower than GYTS 2009 , but the proportion was still high. Support for smoke-free initiatives increased significantly in 2016, where almost 9 in 10 respondents were in favor of the initiatives (Table 3).

\section{Smoking cessation attempt}

Almost 7 in 10 current smokers wanted and attempted to quit smoking (Table 1). The proportion decreased from $79.4 \%$ in 2003 to $74.5 \%$ in 2016 . However, in

Table 2. Prevalence of ever smokers, ever smokers who initiated smoking before age of 10 years, current smokers, and non-smokers susceptible to smoking

\begin{tabular}{|c|c|c|c|c|c|c|c|}
\hline \multirow[t]{2}{*}{ Prevalence of smoking } & \multirow[t]{2}{*}{ Survey } & \multicolumn{2}{|r|}{ Total } & \multicolumn{2}{|r|}{ Male } & \multicolumn{2}{|r|}{ Female } \\
\hline & & $n$ & $\%(95 \%$ CI $)$ & $n$ & $\%(95 \%$ CI $)$ & $n$ & $\%(95 \%$ CI $)$ \\
\hline \multirow{3}{*}{$\begin{array}{l}\text { Ever smoked cigarettes, even one or } \\
\text { two puffs }\end{array}$} & TECMA 2016 & 1258 & $27.3(22.5-32.7)$ & 1109 & $44.9(40.1-49.8)$ & 149 & $7.7(5.2-11.2)$ \\
\hline & GYTS 2009 & 992 & $31.2(29.6-32.9)$ & 740 & $46.9(44.5-49.4)$ & 203 & $13.5(11.8-15.3)$ \\
\hline & GYTS 2003 & 1072 & $32.6(31.0-34.3)$ & 887 & $53.6(51.5-56.6)$ & 184 & $11.4(9.9-13.1)$ \\
\hline \multirow{3}{*}{$\begin{array}{l}\text { Ever smokers who initiated smoking } \\
\text { before age of } 10 \text { years }\end{array}$} & TECMA 2016 & 254 & $22.0(16.0-29.4)$ & 204 & $19.7(14.2-26.2)$ & 50 & $40.1(27.7-53.9)$ \\
\hline & GYTS 2009 & 193 & $22.9(19.6-25.2)$ & 135 & $19.5(16.7-22.6)$ & 58 & $33.0(26.4-40.4)$ \\
\hline & GYTS 2003 & 169 & $16.5(14.3-18.9)$ & 121 & $14.1(11.9-16.7)$ & 48 & $26.2(22.5-36.9)$ \\
\hline \multirow[t]{3}{*}{ Current cigarette smoker } & TECMA 2016 & 611 & $14.8(11.3-19.1)$ & 578 & $26.1(19.9-33.4)$ & 33 & $2.4(1.4-4.1)$ \\
\hline & GYTS 2009 & 554 & 18.5 (17.4-19.9) & 465 & $30.9(29.6-33.3)$ & 80 & $6.1(4.9-7.4)$ \\
\hline & GYTS 2003 & 641 & $19.9(18.5-21.3)$ & 571 & $35.5(33.2-38.0)$ & 70 & $4.3(3.4-5.4)$ \\
\hline \multirow{3}{*}{$\begin{array}{l}\text { Non-smoker likely to initiate smoking } \\
\text { in the next year }\end{array}$} & TECMA 2016 & 387 & $9.6(7.1-12.9)$ & 252 & $14.5(9.5-21.5)$ & 135 & $5.5(4.0-7.6)$ \\
\hline & GYTS 2009 & 691 & $21.7(20.3-23.2)$ & 516 & $31.6(29.6-34.2)$ & 175 & $11.3(9.8-13.0)$ \\
\hline & GYTS 2003 & 860 & $25.8(24.3-27.4)$ & 674 & 39.9 (37.6-42.3) & 196 & $11.3(9.9-13.0)$ \\
\hline
\end{tabular}

Table 3. An attempt for smoking cessation among current smokers

\begin{tabular}{|c|c|c|c|c|c|c|c|}
\hline \multirow[t]{2}{*}{ An attempt for smoking cessation } & \multirow[t]{2}{*}{ Survey } & \multicolumn{2}{|r|}{ Total } & \multicolumn{2}{|r|}{ Male } & \multicolumn{2}{|r|}{ Female } \\
\hline & & $n$ & $\%(95 \%$ CI $)$ & $n$ & $\%(95 \%$ CI $)$ & $n$ & $\%(95 \%$ CI $)$ \\
\hline \multirow{3}{*}{$\begin{array}{l}\text { Current cigarette smoker who wants } \\
\text { to stop smoking }\end{array}$} & TECMA 2016 & 339 & $74.5(61.0-84.6)$ & 323 & $72.3(57.7-83.5)$ & 16 & 100 \\
\hline & GYTS 2009 & 409 & 75.3 (71.4-78.8) & 333 & $76.9(72.7-80.6)$ & 76 & $69.0(59.6-77.0)$ \\
\hline & GYTS 2003 & 428 & $79.4(74.3-83.6)$ & 371 & 79.2 (73.7-83.8) & 57 & $80.6(63.5-90.8)$ \\
\hline \multirow{3}{*}{$\begin{array}{l}\text { Current cigarette smoker who had tried } \\
\text { to stop smoking during the past year }\end{array}$} & TECMA 2016 & 352 & $73.2(64.5-80.5)$ & 335 & $71.1(62.4-78.8)$ & 17 & 91.5 (83.5-99.7) \\
\hline & GYTS 2009 & 465 & $77.7(74.1-80.9)$ & 395 & $80.1(76.3-83.4)$ & 78 & $66.9(57.2-75.4)$ \\
\hline & GYTS 2003 & 550 & 86.8 (83.1-89.8) & 476 & $86.3(81.7-89.8)$ & 74 & 90.5 (83.1-94.9) \\
\hline \multirow{3}{*}{$\begin{array}{l}\text { Current smoker who had ever received } \\
\text { help to stop smoking }\end{array}$} & TECMA 2016 & 432 & $70.2(66.0-74.1)$ & 412 & $72.7(70.2-75.0)$ & 20 & $42.0(19.6-69.1)$ \\
\hline & GYTS 2009 & 669 & $72.5(69.5-75.3)$ & 531 & $76.4(71.0-77.5)$ & 138 & $66.2(59.5-72.4)$ \\
\hline & GYTS 2003 & \multicolumn{6}{|c|}{ Not investigated } \\
\hline
\end{tabular}


2016, all of the smoking female respondents reported contemplating quitting. Seven out of 10 current smokers reported having received assistance to cease smoking, significantly higher in males than in females (Table 4).

\section{Access to tobacco products and health education}

About 3 out of every 5 current smokers in 2003 bought their cigarettes, but the proportion was significantly reduced to 1 in 5 in 2016. The proportion of youth who were refused purchase of cigarettes in shops due to being minors increased from $38.9 \%$ in 2003 to $54.6 \%$ in 2016 . A significant reduction was also observed in the proportion of respondents who were ever offered 'free' cigarettes by cigarette company representatives (from $14.0 \%$ in 2016 to $2.1 \%$ in 2016). A majority of the respondents (approximately $80 \%$ ) were taught about the dangers of tobacco use across the three surveys, and no significant difference was observed between genders (Table 5).

Table 4. Secondhand smoke exposure at home, in public places, and those who think that smoking should be banned in public places

\begin{tabular}{|c|c|c|c|c|c|c|c|}
\hline \multirow[t]{2}{*}{ Secondhand smoke exposure } & \multirow[t]{2}{*}{ Survey } & \multicolumn{2}{|r|}{ Total } & \multicolumn{2}{|r|}{ Male } & \multicolumn{2}{|r|}{ Female } \\
\hline & & $n$ & $\%(95 \%$ CI $)$ & $n$ & $\%(95 \%$ CI $)$ & $n$ & $\%(95 \%$ CI $)$ \\
\hline \multirow{3}{*}{$\begin{array}{l}\text { Exposed to secondhand smoke at } \\
\text { home in the past } 7 \text { days }\end{array}$} & TECMA 2016 & 1890 & $40.2(35.0-45.7)$ & 979 & 39.9 (35.0-44.9) & 911 & $40.6(34.1-47.5)$ \\
\hline & GYTS 2009 & 1540 & $48.5(46.8-50.3)$ & 799 & $49.6(47.2-52.0)$ & 741 & $47.4(44.9-49.9)$ \\
\hline & GYTS 2003 & \multicolumn{6}{|c|}{ Not investigated } \\
\hline \multirow{3}{*}{$\begin{array}{l}\text { Exposed to secondhand smoke in public } \\
\text { places in the past } 7 \text { days }\end{array}$} & TECMA 2016 & 2722 & $53.8(50.2-57.5)$ & 1497 & $56.3(52.1-61.9)$ & 1225 & $51.1(46.9-55.3)$ \\
\hline & GYTS 2009 & 2024 & $63.5(61.8-65.2)$ & 1085 & $66.9(64.5-69.1)$ & 939 & $60.1(57.6-62.5)$ \\
\hline & GYTS 2003 & \multicolumn{6}{|c|}{ Not investigated } \\
\hline \multirow{3}{*}{$\begin{array}{l}\text { Thinks smoking should be banned in } \\
\text { public places }\end{array}$} & TECMA 2016 & 4694 & 87.6 (83.4-90.9) & 2344 & $84.0(80.3-87.2)$ & 2350 & $91.7(85.4-95.4)$ \\
\hline & GYTS 2009 & 2650 & 83.5 (82.1-84.7) & 1273 & 79.5 (77.4-81.8) & 189 & $87.5(85.7-89.1)$ \\
\hline & GYTS 2003 & 2731 & $80.8(78.1-83.3)$ & 1312 & 77.4 (73.6-80.7) & 1419 & $84.3(81.6-86.6)$ \\
\hline
\end{tabular}

Table 5. Access and availability of cigarettes to smokers and Health Education

\begin{tabular}{|c|c|c|c|c|c|c|c|}
\hline \multirow{2}{*}{$\begin{array}{l}\text { Access and availability of cigarettes } \\
\text { to smokers and Health Education }\end{array}$} & \multirow[t]{2}{*}{ Survey } & \multicolumn{2}{|r|}{ Total } & \multicolumn{2}{|r|}{ Male } & \multicolumn{2}{|r|}{ Female } \\
\hline & & $n$ & $\%(95 \% \mathrm{CI})$ & $n$ & $\%(95 \%$ CI $)$ & $n$ & $\%(95 \%$ CI $)$ \\
\hline \multirow{3}{*}{$\begin{array}{l}\text { Current smoker who usually buys } \\
\text { cigarettes in a store }\end{array}$} & TECMA 2016 & 221 & $22.8(17.2-39.5)$ & 212 & $25.0(18.2-33.4)$ & 9 & $8.0(2.6-22.5)$ \\
\hline & GYTS 2009 & 309 & $50.2(49.4-54.2)$ & 270 & $53.8(49.4-58.1)$ & 39 & $34.6(26.3-44.0)$ \\
\hline & GYTS 2003 & 393 & $58.0(53.8-62.1)$ & 361 & $61.0(56.8-65.1)$ & 32 & $36.9(27.4-47.6)$ \\
\hline \multirow{3}{*}{$\begin{array}{l}\text { Current smoker who usually buys } \\
\text { cigarettes in a store and ever denied } \\
\text { purchase of cigarettes being a minor }\end{array}$} & TECMA 2016 & 182 & $54.6(45.2-63.6)$ & 176 & $57.0(48.5-65.2)$ & 6 & $30.8(9.7-64.8)$ \\
\hline & GYTS 2009 & 267 & $49.8(45.5-54.0)$ & 211 & $49.2(44.5-53.9)$ & 56 & $52.0(42.54-61.4)$ \\
\hline & GYTS 2003 & 134 & $38.9(31.8-46.4)$ & 122 & $38.4(31.14-46.3)$ & 12 & $44.0(23.7-66.0)$ \\
\hline \multirow{3}{*}{$\begin{array}{l}\text { Ever offered 'free' cigarettes by a } \\
\text { cigarette company representative }\end{array}$} & TECMA 2016 & 99 & $2.1(1.7-2.9)$ & 83 & $3.6(2.6-4.8)$ & 16 & $0.5(0.3-1.1)$ \\
\hline & GYTS 2009 & 182 & $5.9(5.1-6.8)$ & 120 & 7.5 (6.3-9.0) & 62 & $4.2(3.3-5.4)$ \\
\hline & GYTS 2003 & 50 & $14.0(10.5-18.4)$ & 50 & $15.3(10.5-18.4)$ & - & - \\
\hline \multirow{3}{*}{$\begin{array}{l}\text { Ever had education in school on } \\
\text { dangers of smoking tobacco, in the } \\
\text { past year }\end{array}$} & TECMA 2016 & 4018 & $86.4(81.7-90.1)$ & 2041 & 85.2 (81.6-88.3) & 1977 & 87.8 (81.4-92.2) \\
\hline & GYTS 2009 & 2469 & 77.7 (76.2-79.2) & 1220 & 74.7 (72.5-76.8) & 1269 & 80.7 (78.7-82.6) \\
\hline & GYTS 2003 & 2427 & $82.0(78.9-84.7)$ & 1230 & $81.7(78.8-84.4)$ & 1197 & 82.8 (78.5-85.5) \\
\hline
\end{tabular}




\section{DISCUSSION}

This study is one of the first comprehensive evaluations of the problem of smoking among middle-school students in Malaysia. We found the prevalence of current smokers to be on a downward trend from 2003 to 2016. Similar findings were reported by MiguelBaquilod et al. ${ }^{18}$ among school-going adolescents in their surveys in 2000 and 2003. However, no similar pattern was observed in two waves of Global Youth Tobacco Survey (GYTS) among school-going adolescents in India ${ }^{19}$ and in Italy ${ }^{20}$. The latest prevalence of $14.8 \%$ was similar to the GYTS survey in the Philippines in $2015^{21}$. However, it is double the rate of $6.7 \%$ reported in Bangladesh ${ }^{22}$ as well as $10 \%, 12.5 \%$ and $13.6 \%$ from surveys in Thailand ${ }^{23}$, Indonesia ${ }^{24}$, and 68 lower-income and middle-income countries $^{25}$, respectively, although it is 5 percentage points lower than the study reported among youths in Italy $^{20}$. Our study also found that current smoking was significantly higher among males compared to females (ratio 10:1). This is in agreement with several local studies in Indonesia ${ }^{9,12,13,24}$. However, it is in contrast to findings among youths in Italy ${ }^{20}$, which reported a similar proportion of current smokers among boys and girls. We postulate that the results might be due to the local Asian social norm that does not accept female smokers ${ }^{9}$, which has the effect of preventing females from smoking. In addition, the parents and guardians in the local community pay more attention to their daughters, which might be another reason for the findings in this study ${ }^{9}$. The findings suggest that more intervention and anti-smoking measures should target male adolescents in order to reduce the incidence of smoking initiation among them.

Our study also found that approximately 1 in 10 non-smokers intended to initiate smoking in the next year; $16.2 \%$ and $12.1 \%$ points lower than in 2003 and 2009, respectively. The same finding was also observed in the Philippines, which reported a significant reduction in susceptibility to smoking among youth from 2000 to $2003^{18}$. However, the findings contradict the increasing trend of susceptibility to smoking among youth in Botswana, which increased from $14.5 \%$ in 2001 to $31.5 \%$ in $2008^{26}$, and the recent study of Kamke et al. ${ }^{27}$ among youth in USA, where smoking susceptibility among girls was 20-23\% between 1999 and 2011 and increased to $27-29 \%$ between 2014 and 2018, whilst the prevalence among boys was $20-23 \%$ between 1999 and 2011 and increased to $27-31 \%$ between 2014 and 2018. The prevalence of susceptibility to smoking in this study was lower than the $12.5 \%$ reported globally ${ }^{28}$. However, the prevalence was similar to the $10.1 \%$ reported among school-going adolescents in Thailand ${ }^{29}$. The significant reduction of smoking prevalence from 2003 to 2009 might be due to health promotion and comprehensive legislation implemented since 2005, which created a non-conducive environment for smoking among youth. The prevalence of susceptibility to smoking was significantly higher among males, in line with previous findings $\mathrm{s}^{30,31}$ and those of Lee et al. ${ }^{9}$ among Thai youth. This may be explained by male smoking having been accepted as a norm in society ${ }^{9}$.

We predict low incidence of future smoking initiation among Malaysian school-going adolescents based on the findings of the present study. However, the existing anti-smoking measures should be strengthened, with focus on early adolescents to further reduce smoking incidence. One in five adolescent smokers started smoking before the age of 10 years, and the proportion has plateaued since 2009 , albeit lower than the four out of ten smokers reported among adolescent students in Bangladesh ${ }^{32}$. The findings suggest that more robust and comprehensive measures involving parents or guardians and the school administrators are urgently needed to address the adolescent smoking.

\section{SHS exposure}

The study found a significant reduction in SHS exposure in public areas and at home over the eight-year period. However, the latest prevalence is still high compared to other studies that reported approximately $30.4 \%$ and $44.2 \%$ of adolescents in 168 lower- and middle-income countries (LMICs) ${ }^{33}$, and about $21 \%$ and $39 \%$ in 25 African countries ${ }^{34}$, exposed to SHS inside and outside of homes, respectively. However, it is lower than $70.0 \%$ (inside the house) and $67.4 \%$ (outside the house) reported among youth in Greece ${ }^{35}$, although a decrease in SHS exposure was observed. The prevalence of exposure to SHS remains at levels that will cause major public health problems in the future and does not comply with Article 8 of the World Health Organization (WHO) FCTC, which highlights the importance of protection from 
exposure to tobacco smoke. It is also well known that SHS has been classified by the International Agency for Research on Cancer as a human carcinogen ${ }^{36}$. Therefore, there is a need to increase the enforcement of existing laws governing smoking and exposure to secondhand smoke in public places. In addition, creating more smoke-free areas and educating the public about the dangers of secondhand smoke will have complementary effects in reducing SHS exposure among people who do not smoke, especially children and adolescents ${ }^{37}$.

Furthermore, health promotion and smoking cessation programmes that target parents/guardians who smoke can be another strategy to reduce the SHS exposure at home. The studies have shown that SHS exposure was high among youth if their parents/guardians smoke ${ }^{38,39}$. With knowledge, the smoking parent/guardian might be more motivated to smoke outside the house ${ }^{40}$; in addition, community intervention recruiting the adults should be intensified to promote smoke-free homes and increase the smoking cessation rate, which will ultimately reduce the SHS exposure at home ${ }^{41}$. Studies revealed that the implementation of a smoke-free home is possible with the consent of parents/guardians, especially in the patriarchal society of Malaysia?

In 2016, only one in five current smokers bought cigarettes from stores themselves, significantly lower than in 2003 (three in five) and in 2009 (50\%). The proportion is similar to the $22.6 \%$ in Uganda, lower than $26.9 \%$ in Ghana, $28.2 \%$ in Swaziland, $37.7 \%$ in the Republic of Congo, 52.6\% in South Africa ${ }^{42}$, and $79.4 \%$ in the Philippines ${ }^{21}$. The reduction of almost $30 \%$ might be due to a regulation restricting an individual younger than 18 years old to possess cigarettes ${ }^{3}$. The study also revealed that the proportion of smokers who obtained cigarettes was significantly higher among current male smokers across the survey. This might be due to the social norm, whereby smoking among females is disapproved, thus reducing the proportion of female smokers purchasing cigarettes from stores.

Approximately $45.4 \%$ of smokers were not refused purchase of cigarettes in 2016, although the proportion is higher compared to those reported in 2003 and 2009. In addition, the prevalence was significantly lower compared to $90 \%$ reported by Zulkifli and Rogayah ${ }^{43}$ and among youth in Greece ${ }^{35}$.
The proportion is still substantial, given the smoking regulation, which prohibits the sale of cigarettes to individual younger than 18 years old since $2004^{10}$. The call for more stringent enforcement activities should be carried out in premises selling tobacco products. As stipulated in the regulation, the study also indicated a need to develop and implement legislation on the access of cigarettes by licensing the premises selling cigarettes, as a substantial proportion of minors are still able to buy cigarettes from stores, as implementation of the rules has been shown to significantly reduce youths' access to tobacco products ${ }^{44,45}$. Our study also found that only a small proportion of adolescents have ever been offered cigarette products by tobacco industry representatives, $2 \%$ lower than a study from six African countries (ranging from $4.7 \%$ in Cote d'Ivoire to $12.1 \%$ in South Africa $)^{42}$. This finding suggests that continuous efforts should be made to deter this tactic by cigarette companies.

About three-quarters of current smokers wanted to stop smoking and had tried to quit smoking in the past year, across all three surveys, similar to school-going adolescents in Indonesia ${ }^{24}$, but lower than in the Philippines GYTS survey $(90 \%)^{21}$. The unchanging trend suggests a need to develop, pilottest, and evaluate potential youth cessation programs. Once effective programs have been identified, they need to be implemented throughout the country. A significantly lower proportion of female smokers seek assistance to quit smoking compared to male smokers across the surveys, which is similar to a finding in Indonesia ${ }^{24}$. We postulate that the social norms that stigmatize female smoking hinders female smokers from coming forward to seek assistance to quit smoking.

\section{Limitations}

Several limitations of our study need to be acknowledged. First, there were non-responses in our study that may have introduced selection bias if they were associated with smoking. In addition, the possibility of information or recall bias cannot be excluded given that some students may not provide correct answers and also may under-report the level of smoking, since the data collected are based on a self-administered questionnaire. However, some previous studies have indicated a high correlation 
between self-reported and biochemically-verified smoking status ${ }^{46,47}$. Second, the data represent only youths who are enrolled in school, which might limit the generalizability to all youths aged 13-15 years in Malaysia. However, the majority of Malaysian adolescents aged 13-15 years attend school as public school education is free ${ }^{9}$. Nevertheless, the surveys achieved a high participation rate, sufficient for drawing firm conclusions, and used a standardized questionnaire, which enables cross-country comparisons. Although the GYTS is cross-sectional, it is a valid and reliable means of tracking changes in the population's smoking behavior over time and for planning future tobacco control programs.

\section{CONCLUSIONS}

An important finding of the study is the significant reduction in ever and current smoking, intention to smoke within one year, secondhand exposure in public places and homes, access to cigarette products in stores, and offers of 'free' cigarette products, among adolescents. However, prevalence of current smoking is still high, and a large proportion of adolescents are still exposed to secondhand smoke and are able to buy tobacco products in stores. The proportion of adolescent smokers who seek assistance to quit and ever taught about the dangers of smoking have also remained stagnant for the past 15 years. The Ministry of Health of Malaysia should involve all stakeholders to formulate and develop a comprehensive tobacco control program to tackle smoking and SHS exposure among children and adolescents, and assess periodically the above measures to evaluate the effectiveness of the implemented programs.

\section{REFERENCES}

1. World Health Organization. WHO Report on the Global Tobacco Epidemic, 2008: The MPOWER package. https:// apps.who.int/iris/bitstream/ pdf;jsessionid=13F189DFA handle/10665/43818/9789241596282_eng.CDFB5F3 ECC543000DB9466A?sequence $=1$. Accessed September 16, 2020.

2. Institute of Public Health. [National Health and Morbidity Survey 2015. Report on smoking status among Malaysian adults]. Malaysian Ministry of Health; 2015.

3. Malaysian Ministry of Health. [National Strategic Plan on Tobacco Control 2015-2020: Strategic planning on smoking]. Malaysia: Ministry of Health; 2014.

4. Institute of Public Health. [Report of the Global Adults Tobacco Survey (GATS) Malaysia 2011]. Malaysian
Ministry of Health; 2012.

5. U. S. Department of Health and Human Services. Preventing tobacco use among youth and young adults: a report of the Surgeon General. Washington, D.C.: Department of Health and Human Services, Centers for Disease Control and Prevention, National

6. Hegmann KT, Fraser AM, Keaney RP, et al. The effect of age at smoking initiation on lung cancer risk. Epidemiology. 1993;4(5):444-448. doi:10.1097/00001648-19930900000010

7. Taioli E, Wynder EL. Effect of the age at which smoking begins on frequency of smoking in adulthood. N Engl J Med. 1991;325(13):968-969. doi:10.1056/NEJM199109263251318

8. Reidpath DD, Davey TM, Kadirvelu A, Soyiri IN, Allotey $P$. Does one cigarette make an adolescent smoker, and is it influenced by age and age of smoking initiation? Evidence of association from the US Youth Risk Behavior Surveillance System 2011. Prev Med. 2014;59:37-41. doi:10.1016/j.ypmed.2013.11.011

9. Lim KH, Lim HL, Teh CH, et al. Smoking among schoolgoing adolescents in selected secondary schools in Peninsular Malaysia - findings from the Malaysian Adolescent Health Risk Behaviour (MyaHRB) study. Tob Induc Dis. 2017;15(January). doi:10.1186/s12971-016-0108-5

10. Government of Malaysia. Food Act 1993: Control of tobacco product regulations 2004.

11. World Health Organization. MPOWER in action. https://www.who.int/tobacco/mpower/publications/ brochure_2013/en/. Published December 23, 2013. Accessed May 6, 2020.

12. Shamsuddin K, Haris MF. Family influence on current smoking habits among secondary school children in Kota Bharu, Kelantan. Singapore Med J. 2000;41(4): 167-171. PMID: 11063181.

13. Lim KH, Teh CH, Lim HL, et al. Smoking among Secondary School Students in Kota Tinggi, Johor, Malaysia - Findings from a Cross-Sectional Study. Asian Pac J Cancer Prev. 2015;16(11):4563-4570. doi:10.7314/apjcp.2015.16.11.4563

14. Institute of Public Health. [Third National Health and Morbidity Survey 2006: smoking]. Malaysian Ministry of Health; 2008.

15. Lim KH, Teh CH, Heng PP, et al. Source of cigarettes among youth smokers in Malaysia: Findings from the tobacco and e-cigarette survey among Malaysian school adolescents (TECMA). Tob Induc Dis. 2018;16(November). doi:10.18332/tid/96297

16. Global Youth Tobacco Survey Collaborative Group. Tobacco use among youth: a cross-country comparison. Tob Control. 2002;11(3):252-270. doi:10.1136/tc.11.3.252

17. Centers for Disease Control and Prevention. National Health Interview Survey: Glossary. https://www.cdc.gov/ nchs/nhis/tobacco/tobacco_glossary.htm. Accessed July $1,2020$.

18. Miguel-Baquilod M, Fishburn B, Warren CW, Jones NR, 
Asma S. Linking Global Youth Tobacco Survey (GYTS) data to the WHO Framework Convention on Tobacco Control (FCTC): the case for the Philippines. Prev Med. 2008;47 Suppl 1: S27-S32. doi:10.1016/j.ypmed.2008.02.009

19. Gajalakshmi V, Kanimozhi CV. A Survey of 24,000 Students Aged 13-15 Years in India: Global Youth Tobacco Survey 2006 and 2009. Tob Use Insights. 2010;3:23-31. doi:10.1177/1179173X1000300001

20. Gorini G, Gallus S, Carreras G, et al. Prevalence of tobacco smoking and electronic cigarette use among adolescents in Italy: Global Youth Tobacco Surveys (GYTS), 2010, 2014, 2018. Prev Med. 2020;131:105903. doi:10.1016/j.ypmed.2019.105903

21. World Health Organization. Global Youth Tobacco survey 2015. Philippines 2016.

22. Khan JR, Raheem E, Daniel M. The prevalence and correlates of tobacco use among 7-9th grade students in Bangladesh. Child Youth Serv Rev. 2019;104:104406. doi:10.1016/j.childyouth.2019.104406

23. Sirichotiratana N, Techatraisakdi C, Rahman K. et al. Prevalence of smoking and other smoking-related behaviors reported by the Global Youth Tobacco Survey (GYTS) in Thailand. BMC Public Health. 2008;8(Suppl 1):S3-S10. doi:10.1186/1471-2458-8-S1-S3

24. Aditama TY, Pradono J, Rahman K, et al. Linking Global Youth Tobacco Survey (GYTS) Data to the WHO Framework Convention on Tobacco Control: The Case for Indonesia. Prev Med. 2008;47(Supplement 1):S11-S14. doi:10.1016/j.ypmed.2008.05.003

25. Xi B, Liang Y, Liu Y, et al. Tobacco use and secondhand smoke exposure in young adolescents aged 12-15 years: data from 68 low-income and middle-income countries. Lancet Glob Health. 2016;4(11):e795-e805. doi:10.1016/s2214-109x(16)30187-5

26. English LM, Hsia J, Malarcher A. Tobacco advertising, promotion, and sponsorship (TAPS) exposure, antiTAPS policies, and students' smoking behavior in Botswana and South Africa. Prev Med. 2016;91:S28-S34. doi:10.1016/j.ypmed.2016.01.014

27. Kamke K, Sabado-Liwag M, Rodriquez EJ, Pérez-Stable EJ, El-Toukhy S. Adolescent Smoking Susceptibility: GenderStratified Racial and Ethnic Differences, 1999-2018. Am J Prev Med. 2020;58(5). doi:10.1016/j.amepre.2019.11.023

28. Veeranki SP, Mamudu HM, Anderson JL, Zheng S. Worldwide never-smoking youth susceptibility to smoking. J Adolesc Health. 2014;54:144-150. doi:10.1016/j.jadohealth.2013.07.036

29. Lee G, Lee J, Lee S. Risk factors of future smoking among Thai youth: a secondary analysis of the Thai Global Youth Tobacco Survey. Asia Pac J Public Health. 2015;27(2):NP2602NP2609. doi:10.1177/1010539513487015

30. Lim KH, Chong ZL, Khoo YY, Kaur J. Parental smoking status, stress, anxiety, and depression are associated with susceptibility to smoking among non-smoking school adolescents in Malaysia. Asia
Pac J Public Health. 2014;26(5 Suppl):81S-90S. doi:10.1177/1010539514542426

31. Lim KH, Ghazali SM, Lim HL, et al. Smoking susceptibility among non-smoking school-going adolescents in Malaysia: findings from a national school-based survey. BMJ Open. 2019;9(10):e031164. doi:10.1136/bmjopen-2019-031164

32. Islam SM, Mainuddin AK, Bhuiyan FA, Chowdhury KN. Prevalence of tobacco use and its contributing factors among adolescents in Bangladesh: Results from a population-based study. South Asian J Cancer. 2016;5(4):186-188. doi:10.4103/2278-330X.195339

33. Veeranki PS, Mamudu HM, Zheng S, et al. Secondhand smoke exposure among never-smoking youth in 168 countries. J Adolesc Health. 2015;56(2):167-173. doi:10.1016/j.jadohealth.2014.09.014

34. Owusu D, Mamudu HM, John RM, Ibrahim A, Ouma AEO, Veeranki SP. Never-Smoking Adolescents' Exposure to Secondhand Smoke in Africa. Am J Prev Med. 2016;51(6):983-998. doi:10.1016/j.amepre.2016.08.040

35. Rachiotis G, Barbouni A, Basagiannis A, et al. Prevalence and determinants of current cigarette smoking and secondhand smoking among Greek adolescents: the Global Youth Tobacco Survey (GYTS) 2013 study. BMJ Open. 2020;10(2):e034760. doi:10.1136/bmjopen-2019-034760

36. IARC Working Group on the Evaluation of Carcinogenic Risks to Humans. Tobacco smoke and involuntary smoking. IARC Monographs on the evaluation of carcinogenic risks to humans. Volume 83. Lyon, France: International Agency for Research on Cancer; 2004.

37. Lim KH, Teh CH, Nik Mohamed MH, et al. Exposure to tobacco second-hand smoke and its associated factors among non-smoking adults in smoking-restricted and non-restricted areas: Findings from a nationwide study in Malaysia. BMJ Open. 2018;8:e017203. doi:10.1136/bmjopen-2017-017203

38. Lim HL, Teh CH, Kee CC, Ghazali SM, Pan S a/1, Lim KH. Exposure to second-hand smoke among secondary school-going adolescents: Findings from the Malaysian Adolescent Health Risk Behaviour (MyAHRB) study. Proceedings of Singapore Healthcare. 2019;28(1):19-25. doi:10.1177/2010105818789961

39. Ghazali SM, Huey TC, Cheong KC, et al. Prevalence and factors associated with second-hand smoke exposure among Malaysian adolescents. Tob Induc Dis. 2019;17(March). doi:10.18332/tid/102728

40. Halterman JS, Conn KM, Hernandez T, Tanski SE. Parent knowledge, attitudes, and household practices regarding SHS exposure: a case-control study of urban children with and without asthma. Clin Pediatr (Phila). 2010;49(8):782-789. doi:10.1177/0009922810368290

41. Caldwell AL, Tingen MS, Nguyen JT, et al. Parental smoking cessation: impacting children's tobacco smoke exposure in the home. Pediatrics. 2018;141(Supplement 1):S96-S106. doi:10.1542/peds.2017-1026M 
42. Chandora R, Song Y, Chaussard M, et al. Youth access to cigarettes in six sub-Saharan African countries. Prev Med. 2016;91S:S23-S27. doi:10.1016/j.ypmed.2016.01.018

43. Zulkifli A, Rogayah J. Cigarette sales to minor in Kelantan. Med J Malaysia. 1998;53(2):128-130.

44. Astor RL, Urman R, Barrington-Trimis JL, et al. Tobacco retail licensing and youth product use. Pediatrics. 2019;143(2):e20173536. doi:10.1542/peds.2017-3536

45. Jin Y, Lu B, Klein EG, Berman M, Foraker RE, Ferketich AK. Tobacco-free pharmacy laws and trends in tobacco retailer density in California and Massachusetts. Am J Public Health. 2016;106(4):679-685. doi:10.2105/AJPH.2015.303040

46. Lim HL, Teh CH, Kee CC, Normala I, Lim KH. Do adolescents under-report their smoking status? - Findings from secondary school students in Kota Tinggi, Johor. International Journal of Public Health and Clinical Sciences. 2017;4(2):66-72.

47. Ab Manan N, Nawi AM, Ahmad N, Hassan MR. Selfreported smoking among adolescents: How accurate is it with the urine cotinine strip test? Int J Pediatr Adolesc Med. 2020;7(2). doi:10.1016/j.ijpam.2019.08.001

\section{ACKNOWLEDGEMENTS}

We thank the Director-General of Health, Malaysia, for his permission to publish this article. We also thank those who were involved in the study and those who assisted in the collection and management of the data for their support and cooperation.

CONFLICTS OF INTEREST

The authors have completed and submitted the ICMJE Form for Disclosure of Potential Conflicts of Interest and none was reported.

\section{FUNDING}

The project was funded by the National Institute of Health, Ministry of Health, Malaysia.

\section{AUTHORS' CONTRIBUTIONS}

$\mathrm{KHL}, \mathrm{JHL}$ and $\mathrm{HLL}$ wrote the manuscript. SMG, PPH and $\mathrm{CHT}$ carried out data management, data cleaning and statistical analysis. CCK, YLC, JHL and $\mathrm{CHT}$ designed the study and calculated the sample size required. CHT, HLL, SMG and BSGPS were responsible for data collection, quality assurance, and coordination of the study. CHT, CCK and HLL were involved in the interpretation and implications of the data. All authors reviewed and read the manuscript, and agreed on the final version.

PROVENANCE AND PEER REVIEW

Not commissioned; externally peer reviewed. 